\title{
KESULTANAN BANJAR DAN KEPENTINGAN DAKWAH ISLAM
}

\author{
Kamrani Buseri*
}

\begin{abstract}
Kajian ini membahas tentang penyebaran Islam sejak kerajaan Banjar pada abad ke- 16. Perkembangan Islam di Banjarmasin didukung oleh kerajaan Banjar, yang menganut agama Islam dan memberikan pengarub kepada masyarakatnya untuk menganut agama Islam. Sultan Suriansyah sebagai Sultan Banjar yang pertama mengupayakan penyebaran Islam dengan pengkaderan ulama, yaitu dengan mengirim Syekh Arsyad Al-Banjary, yang kemudian dikenal sebagai ulama Banjar yang tersohor, babkan di luar Nusantara. Dengan buku-buku beliau yang ada, ajaran beliau sampai sekarang masib berkembang, ajaran yang dinamis, yang memberikan adaptasi budaya Islam yang sesuai dengan kekhasan corak daerah Banjar yang sangat kaya dan bervariasi.
\end{abstract}

Kata Kunci: $\quad$ Agama, Dakwah, Kesultanan, Kerajaan, Budaya, Masyarakat

\section{Agama dan Dakwah Kesultanan Dulu}

Agama Islam adalah agama resmi kerajaan Banjar, karena sejak berdirinya, kerajaan Banjar menjadikan Islam sebagai agama resmi. A Ghazali Usman dalam sebuah seminar menyatakan bahwa masyarakat Banjar itu terbentuk bersamaan dengan berdirinya kerajaan Islam di Bandjarmasih (sekarang Banjarmasin) pada tahun 1526. Kerajaan ini seperti diutarakan dalam Hikayat Banjar didirikan oleh Raden Samudra, pangeran mahkota yang terbuang dari kerajaan Hindu di Negaradaha dari pamannya sendiri, yaitu pangeran Tumanggung, setelah ia memperoleh bantuan pasukan sukarelawan dari kerajaan Islam Demak (Jawa). Segera setelah itu ia memindahkan pusat pemerintahan ke Banjarmasin. Raden Samudera sendiri kemudian memeluk agama Islam dan menjadikan agama ini sebagai agama kerajaan. Sejak itu ia bergelar Sultan Suriansyah. Rakyatnya yang beragama Islam baik orang-orang

${ }^{*}$ Guru Besar Ilmu Pendidikan Islam, pengajar Ilmu Pendidikan Islam, Filsafat Ilmu dan Manajemen Pendidikan Islam pada Pascasarjana IAIN Antasari, Ketua Dewan Pengawas Syariah Bank Kalimantan Selatan, Asesor Badan Akreditasi Nasional Perguruan Tinggi (BAN PT) dan Ketua Dewan Penasehat Majelis Ulama Indonesia Provinsi Kalimantan Selatan. 
Melayu, Jawa maupun Dayak (Ngaju, Maanyan, Lalawangan dan Bukit) merupakan unsur-unsur utama terbentuknya masyarakat Banjar. ${ }^{1}$

Menurut H. Gt. Abdul Muis, Agama Islam masuk ke daerah Kalimantan Selatan sekitar permulaan abad ke $16 \mathrm{M}$. dibawa oleh para pedagang dan mubaligh lewat pantai utara Jawa Timur. ${ }^{2}$ Islam sebenarnya sudah mulai dianut oleh sebagian masyarakat sebelum berdirinya Kerajaan Banjar, akan tetapi setelah kerajaan Banjar berdiri, maka seluruh masyarakatnya memeluk Islam, karena Islam dijadikan agama resmi kerajaan, dan perkembangan agama Islam pun berkembang pesat sekali. Akan tetapi perkembangan masuknya Islam tersebut tidak diimbangi dengan perkembangan pengetahuan keislaman masyarakatnya, sampai kembalinya Syekh Muhammad Arsyad al-Banjari (17101812) dari Mekkah setelah belajar di sana selama 30 tahun.

Berkembangnya Islam semenjak awal berdirinya kerajaan justru didukung oleh Sultan Suriansyah sebagai sultan pertama kerajaan Banjar. Ahmad Bardjie menggambarkan bahwa begitu Pengeran Samudra atau Sultan Suriansyah (1520-1546) sekeluarga masuk Islam, Kesultanan Banjar langsung berperan aktif sebagai pendukung dakwah Islamiyah. Hal itu terlihat di hampir semua wilayah kekuasaan kesultanan, mayoritas rakyatnya beragama Islam, ini berarti Sultan sangat berperan dalam menyukseskan dakwah ${ }^{3}$. Lebih jauh Ahmad Bardjie menguraikan bahwa semenjak Sultan Suriansyah, beberapa poin dakwah Islamiyah dilakukan antara lain mendorong agar ada kader ulama mengingat ulama pada waktu itu masih sedikit. Sultan Tamjidillah I mengirim Muhammad Arsyad Al-Banjari untuk belajar ke Mekkah yang sepulangnya menjadi ulama dan berdakwah yang dipusatkan di kampung Dalam Pagar Martapura. Ke sinilah para penuntut ilmu berdatangan, selain dari Martapura juga berdatangan dari Banjarmasin, Nagara dan dari Hulu Sungai. Di lain pihak para Sultan juga memfasilitasi tempat pengajian para ulama, juga mendorong ulama agar aktif membimbing umat secara tertulis, maka ulama seperti Syekh Muhammad Arsyad didorong menulis buku/kitab sebagai pegangan umat. Mengapa tidak langsung menggunakan kitab-kitab dari Timur Tengah, di mana Syekh Arsyad sangat menguasainya. Boleh jadi karena Sultan dan Syekh Arsyad melihat ada keberagamaan masyarakat Banjar yang lebih spesifik dan

\footnotetext{
${ }^{1}$ Analiansyah dkk., Aspirasi Pendidikan Masyarakat Banjar, Antasari Press, Banjarmasin, 2007, h. 7-8.

${ }^{2}$ Analiansyah dkk., Aspirasi Pendidikan ..., h. 8.

${ }^{3}$ Ahmad Bardjie B, Refleksi Banua Banjar: Kumpulan Tulisan Seputar Kesultanan Banjar, Sejarah, Agama dan Sosial Budaya, (Martapura: Pustaka Agung Kesultanan Banjar, 2011), h. 6.
} 
lokalistik yang tidak selalu sama dengan keislaman di tanah Arab. Berarti cara berpikir Sultan dan ulama saat itu sangat dinamis dengan memperhatikan realitas sosial masyarakatnya. ${ }^{4}$

Syech Arsyad merupakan salah seorang tokoh sentral pembaharuan di Nusantara khususnya wilayah kesultanan Banjar mengusung faham neosufisme yang berarti harmonisasi antara ajaran syariat dan tasawuf (fikihsufistik/tasawuf-syar'i). ${ }^{5}$ Kemampuan menulis Syekh Arsyad luar biasa, bahkan belum ada ulama belakangan yang sebanding dengan beliau. Menurut Asywadi Syukur dan Abu Daudi, ada 12 kitab karangan Syekh Arsyad, dan menurut Moh. Shaghir Abdullah ada 15 buah. $^{6}$

Upaya pembaharuan yang dilakukan Syekh Arsyad membuat jumlah masyarakat muslim Banjar yang semula minoritas dan dianut oleh kalangan sekitar keraton, kini menjadi masyarakat muslim mayoritas yang loyal dengan Islam. Realitas inipun sering dikaitkan dengan usaha-usaha para da'i yang biasanya adalah murid sekaligus anak cucu Syekh Arsyad sendiri yang diutus oleh beliau ke pelosok wilayah kesultanan Banjar dan sekitarnya. ${ }^{7}$

\section{Masyarakat Dalam Bingkai Budaya dan Agama}

Budaya yang merupakan hasil cipta, rasa dan karsa manusia bisa berbentuk pisik material dan bisa berbentuk spiritual. Oleh karena itu, kita mengenal budaya material dan budaya spiritual. Sementara esensi budaya adalah nilai-nilai yakni sesuatu yang dianggap berharga oleh manusia dan masyarakatnya. Nilai-nilai tersebut tidak terlepas dari keyakinan yang dianut mereka. Masyarakat Banjar yang memiliki karakteristik muslim, maka dengan meyakini terhadap Islam sebagai ajaran, akan banyak mempengaruhi nilai-nilai yang dihargai mereka, dan tentu saja berpengaruh terhadap budaya mereka.

Apabila di awal kelahiran kesultanan Banjar, agama menjadi bingkai bagi kehidupan bernegara dan berbangsa, maka budaya yang dikembangkan juga budaya yang sejalan dan selaras dengan agama.

${ }^{4}$ Ahmad Bardjie B, Refleksi Banua Banjar ..., h. 7-8.

${ }^{5}$ Ahmad Bardjie B, Refleksi Banua Banjar ..., h. 9.

${ }^{6}$ Fathullah Munadi, Syekh Muhammad Arsyad Al-Banjari: Dalam Konteks Kajian Al-Quran di Nusantara, Antasari Press, Banjarmasin, 2010, h. 51.

${ }^{7}$ Fathullah Munadi, Syekh Mubammad Arsyad ..., h. 61-62, dikutip dari Kiprah Zuriat Muhammad Arsyad dalam Dakwah dan Pendidikan (Daudi, Maulana Syekh Mubammad Arsyad, h. 250-257). 
Bukti sejarah menjelaskan bahwa kerajaan Islam Banjar tidak bisa dipisahkan dengan bangkitnya budaya spiritual karena sejak berdirinya, Islam resmi menjadi agama kerajaan yang diikuti dan dianut oleh seluruh lapisan masyarakat sekaligus menjadi identitas mereka, sehingga suku Banjar identik dengan Islam. Sejak itu pula masyarakat meninggalkan kepercayaan sebelumnya yakni animisme maupun Hindu. Pangeran Samudera sebagai raja pertama memakai nama dan gelar baru yakni Sultan Suriansyah, dan semenjak itu pula muncul istilah kesultanan Banjar. Sejak berdirinya kesultanan Islam Banjar itu, sebenarnya budaya yang dikembangkan oleh kesultanan lebih menekankan pada budaya spiritual (Islam), meskipun tidak meninggalkan budaya material karena Islam adalah agama seimbang tetapi budaya spiritual tetap sebagai fondasinya. ${ }^{8}$

Budaya spiritual merasuk dalam berbagai aspek kehidupan masyarakat Banjar, sebagai contoh, bahwa rumah panggung dibangun oleh urang bahari menggunakan konsep-konsep budaya Banjar yang religius dan sarat makna serta filosofi. ' Lihat saja tentang filosofi religi dan budaya pada pembangunan rumah bubungan tinggi menjulang ke langit merupakan tanda ikrar pengakuan terhadap Allah swt. bagian atas bangunan rumah Banjar bersudut lima merupakan manifestasi rukun Islam yang berjumlah lima. Unsur hitungan panjang, lebar dan tinggi harus ganjil karena sesuai dengan sifat dan nama Allah swt. yang berjumlah ganjil, dan Allah menyukai bilangan ganjil. Belum lagi pada ornamen-ornamen rumah panggung yang kaya akan makna dan simbol keseimbangan hubungan antara manusia, alam dan Sang Pencipta.

Berkenaan dengan budaya spiritual ini juga tampak pada siklus kehidupan masyarakat Banjar semenjak kelahiran hingga kematian. Ada beberapa di antaranya yang dari hari ke hari telah dimodifikasi dan disesuaikan dengan ajaran Islam, sesuai perkembangan ilmu pengetahuan keislaman masyarakat saat ini, sehingga lebih menonjol aspek Islamnya bukan lagi budayanya. Namun demikian beberapa bagian tertentu yang dianggap hanya asesores dibiarkan berkembang hingga saat ini. Acara mandi tujuh bulan kehamilan, batampung tawar, batumbang, baayun anak. Baayun anak sebagian tidak dikerjakan lagi, tetapi di Banua Halat Tapin dilestarikan dengan baik.

${ }^{8}$ Kamrani Buseri, makalah Seminar Penguatan Budaya Banjar dan Peran Kesultanan Dalam Menjawab Tantangan Zaman, tanggal 8 Desember 2011 di Banjarmasin, h.1.

${ }^{9}$ Tri Hayat AW dalalm M Rifhan, Harian Media Kalimantan, 28 Nopember 2011. 
Prof. Dr. Alfani Daud ${ }^{10}$ dengan sangat baik dan lengkap menguraikan aspek-aspek budaya masyarakat Banjar dikaitkan dengan siklus kehidupan dan mata pencaharian. Berkenaan dengan menanam padi misalnya digambarkan beliau di beberapa daerah, masyarakat Banjar saat mau manaradak (menyemai). Ada sementara masyarakat yang melakukan bulir-bulir padi dirabun yaitu diasapi di atas api parapen dengan asap menyan sambil mengucapkan "kur sumangat" berkali-kali. Ketika memasukkan padi ke dalam air dibacakan surah Fatihah sekali dan selawat 3 kali. Ada pula sementara masyarakat yang saat mau memasukkan benih padi ke lubang tugal dibacakan tasbib diulangai sampai lubang atau umang ke tiga. Pada saat penanaman padi di sawah biasanya keluarga petani menyiapkan bubur tepung beras yang dinamakan kokoleh, yang akan dimakan bersama di tengah sawah setelah upacara selesai dan sebelum melanjutkan kegiatan menanam selanjutnya. Kokoleh selalu diasosiasikan dengan bapakuleh atau memperoleh hasil.

Pada aspek lain saat mau menuai padi di sawah misalnya, biasanya didahului dengan tapung tawar juga semacam memanggil semangat padi, karena padi dianggap memiliki semangat seperti kehidupan. Ada istilah kuur sumangat dan padi bisa menangis bila cara memanen tidak baik, sehingga ada padi yang lepas dan terbuang begitu saja. Seringkali orang tua memberi nasehat kepada anaknya bahwa satu butir padi itu sangat berharga, karena meskipun hanya satu butir tetap baru didapatkan dengan memakan waktu selama satu tahun, sehingga perlu hati-hati jangan sampai ada yang terbuang percuma meskipun hanya satu butir saja.

Padi sebagai bahan makanan pokok manusia memiliki hubungan spesialis yang menunjukkan keharmonisan hubungan antara alam dengan manusia. Tidak seperti sekarang sesuai dengan perkembangan hubungan manusia dengan alam dimulai dengan hubungan erat atau menyatu antara alam dengan manusia di zaman mitologis, kemudian manusia terpisah dengan alam di zaman positivis, bahkan manusia berhubungan secara fungsional dengan alam yang membikin semakin berjaraknya antara alam dengan manusia, dan alam semaunya diekpolaitasi oleh manusia. Akibat negatifnya sudah banyak dirasakan oleh manusia, karena manusia lupa bahwa dirinya juga adalah bagian dari alam. Alam yang tidak memiliki akal pun bilamana dijajah oleh manusia, mereka juga akan membalas. Hutan digunduli secara berlebihan, sehingga ekologi menjadi rusak akibatnya alam mulai memberontak dengan banjir besar

${ }^{10}$ Alfani Daud, Islam \& Masyarakat Banjar: Diskripsi dan Analisis Kebudayaan Banjar, (Jakarta: PT RajaGrafindo Persada, 1997). 
yang mengerikan manusia. Rumah kaca yang berlebihan merusak ozon, di mana sinar matahari mulai berbuat keras juga kepada manusia.

Batapung tawar yaitu selamatan setelah melahirkan, umumnya sudah diganti dengan aqiqah yang dianjurkan oleh Rasulullah saw, yakni dengan penyembelihan kambing dua ekor untuk anak lelaki dan satu ekor untuk anak perempuan. Kambing dimasak dan diadakan upacara dengan mengundang tetangga dan kaum kerabat. Dalam upacara aqiqah ini terkait acara pemberian nama (tasmiah), mencukur rambut anak (tabliqah) yang rambutnya ditimbang dengan emas (dalam hadits dengan perak) yang dinilai dengan uang kemudian dibagikan kepada fakir miskin, mencelupkan kurma ke mulut anak (tabnikab) oleh seorang yang saleh dengan harapan semoga anak tersebut kelak menjadi orang saleh pula. Di masyarakat Banjar seringkali bukan kurma yang dicelupkan, tetapi mencelupkan kelapa dicampur gula merah dan garam dengan maksud agar anak kelak berbicara dengan lemak manis disenangi temantemannya dan kalau sudah besar disenangi oleh masyarakat.

Pada budaya Banjar dulu sangat harmonis hubungan antara manusia, alam dan Tuhan. Budaya Banjar masa kini hendaknya menyimak hal ini untuk kembali melakukan harmonisasi hubungan ketiganya tentu melalui modifikasi sesuai dengan perkembangan pemikiran dan pengetahuan masyarakat saat ini.

\section{Fungsi-Fungsi Kesultanan di Bidang Dakwah Islam Masa Kini}

Kesultanan Banjar semenjak didirikannya oleh Sultan Suriansyah (15271545) hingga sultan Muhammad Seman (1862-1905), selalu konsisten dalam mempertahankan Islam sebagai agama dan kepercayaan seluruh masyarakat.

Apabila di zaman kesultanan saat itu dakwah terkait langsung dengan kekuasaan, maka saat kesultanan sekarang agaknya sukar dipadukan karena kesultanan saat ini hanya sebagai lembaga pemangku adat dan budaya, bukan lembaga pemerintahan. Oleh karena itu, dakwah bukan lagi sebagai bagian dari kegiatan politik tetapi menjadi bagian dari kegiatan kultural.

Sebagai lembaga kultural, maka fungsi kesultanan dikaitkan dengan dakwah antara lain:

1. Fungsi pengayoman, yakni mengayomi berbagai aktivitas dakwah keislaman yang berada di tengah-tengah masyarakat, meliputi penerapan fungsi-fungsi manajemen terhadap dakwah.

2. Fungsi dinamisator dan inovator dakwah. Artinya selain menjaga agar dakwah bersifat inklusif sesuai dengan apa yang pernah diterapkan oleh 
Syekh Arsyad dengan neo-sufisme/tasawuf-syar'i, juga atas dasar akidah ahlussunnah wal jama'ah, maka dinamisasi dan inovasi tidak boleh lepas rel yang bisa berdampak negatif bagi kemaslahatan masyarakat.

3. Fungsi supporter, artinya kesultanan mengupayakan support terhadap aktivitas dakwah, baik dalam arti finansial, material maupun tenaga. Misalnya ada kegiatan charges juru dakwah per tahunan untuk memberikan pengluasan bekal dakwah mereka. Mungkin dilakukan melalui kerjasama dengan berbagai lembaga pendidikan tinggi di daerah ini.

4. Fungsi katalisator terutama terhadap lembaga atau tenaga dakwah yang berbeda-beda yang memungkinkan terjadinya friksi antar lembaga atau juru dakwah dimaksud.

5. Fungsi supervisor untuk mengevaluasi sekaligus memperbaiki berbagai aktivitas dakwah yang kurang sejalan dengan ideal ajaran Islam, harapan masyarakat maupun pemerintah. Untuk hal ini tentu harus bekerjasama dengan pihak MUI.

\section{E. Ranah Dakwah dan Peran Kesultanan Saat Ini}

Diakui hingga saat ini keberagamaan masyarakat di wilayah kesultanan Banjar dari hari ke hari terus berkembang dan berubah. Kondisi inklusifis merupakan hal yang menggembirakan, akan tetapi perubahan dan perkembangan keberagamaan bukan seluruhnya sesuai dengan apa yang dikehendaki oleh ajaran Islam baik aspek normatif, filosofis, sosiologis maupun psikologis agama.

Beberapa hal yang perlu menjadi perhatian saat ini ialah:

1. Terkait penguatan keberagamaan, yaitu pemahaman yang benar (adequetely) terhadap ajaran Islam misalnya mengenai kesalehan individual dan kesalehan sosial, meluruskan faham kehanifan (satunya kebenaran, kebaikan dan keindahan). Sementara ini ada gejala masyarakat hanya cenderung mencintai kebenaran dan kebaikan, adapun keindahan tertinggalkan sehingga membuang sampah sembarangan masih banyak ditemui.

2. Terkait dengan penguatan pendidikan, terutama penyadaran akan pentingnya pendidikan keluarga, menghargai kualitas yang sesungguhnya bukan kualitas semu, penguatan karakter individu dan bangsa, menjauhkan dari narkoba, pergaulan bebas, dll.

3. Terkait penguatan kemandirian menyangkut penanaman kepribadian yang Islami seperti kerja keras, berkualitas, disiplin, tidak gengsi, sederhana, mulai 
dari diri sendiri. Melalui pembinaan kepribadian itu diharapkan tercapai kehidupan yang layak dan mandiri.

4. Terkait dengan politik dan budaya, yakni menghidupkan amar ma'ruf dan nahi munkar, sehingga terjadi kontrol sosial yang efektif terhadap berbagai penyimpangan seperti $\mathrm{kkn}$ dan manipulasi yang akan berdampak bagi merebaknya kezaliman.

5. Terkait dengan munculnya berbagai aliran dan wacana keislaman yang sering arogan dan merasa benar sendiri; paradigma internal umat ${ }^{11}$ seyogianya didakwahkan agar inklusifisme yang selama ini telah diraih terus dapat dipertahankan.

6. Terkait dengan pembenahan keyakinan atau ideologi kelompok keagamaan yang ekstrim baik liberalisme-pluralisme, maupun fondamentalis-ektrim; gejala yang masih kecil seyogianya segera didekati untuk dikembalikan kepada keyakinan dan ideologi yang mu'tabarah.

7. Terkait dengan pengluasan wawasan keislaman; khusus menyangkut pemeliharaan lingkungan hidup sebagai hal yang sangat penting.

\section{F. Penutup}

Kesultanan Banjar semenjak lahirnya telah terlibat dalam bidang dakwah antara lain dengan mengirim Syekh Asyad ke Mekah untuk mendalami ilmu keislaman dan sekembalinya menjadi juru dakwah yang handal. Kesultanan juga memfasilitasi dakwah yang dijalankan oleh para ulama dan mendorong untuk menulis kitab sebagai bahan dakwah tertulis.

Fungsi dakwah kesultanan seyogianya harus terus diperankan terutama dalam berbagai fungsi seperti pengayoman, dinamisator, inovator, supporter, katalisator dan supervisor.

Beberapa ranah dakwah yang harus diperhatikan oleh kesultanan saat ini meliputi antara lain: penguatan keberagamaan, wawasan pendidikan,

\footnotetext{
${ }^{11}$ Paradigma internal umat itu ialah: paradigma kebenaran minimal yakni bilamana syahadatnya sama, maka dia adalah saudara kita; paradigma semua aliran sama-sama mencari kebenaran maka mari berdo'a semoga aliran yang berbeda dengan kita memperoleh niai 100, kita juga memperoleh nilai 100; paradigma berlomba-lomba untuk kebaikan jangan berlombalomba mencari-cari kesalahan orang lain dan paradigma kesalehan individu adalah hak asasi sementara yang harus dikembangkan adalah kesalehan sosial berupa perbaikan pendidikan, kesehatan dan kesejahteraan masyarakat (Lihat: Kamrani Buseri Antologi Pendidikan Islam dan Dakwah: Pemikiran Teoritis Praktis dan Kontemporer, (Yogyakarta: UII Press, 2003).
} 
kemandirian, politik dan budaya, pembenahan keyakinan dan ideologi, pembenahan aliran dan wacana keagamaan serta pembenahan wawasan keislaman.

\section{Daftar Pustaka}

Analiansyah dkk., Aspirasi Pendidikan Masyarakat Banjar, Banjarmasin, Antasari Press, 2007.

Bardjie B, Ahmad, Refleksi Banua Banjar: Kumpulan Tulisan Seputar Kesultanan Banjar, Sejarah, Agama dan Sosial Budaya, Martapura, Pustaka Agung Kesultanan Banjar, 2011.

Buseri, Kamrani, Antologi Pendidikan Islam dan Dakwah: Pemikiran Teoritis Praktis dan Kontemporer, buku, Yogyakarta, UII Press, 2003.

Buseri, Kamrani, makalah Seminar Penguatan Budaya Banjar dan Peran Kesultanan Dalam Menjawab Tantangan Zaman, tanggal 8 Desember 2011 di Banjarmasin.

Daud, Alfani, Islam \& Masyarakat Banjar: Diskripsi dan Analisis Kebudayaan Banjar, Jakarta, PT RajaGrafindo Persada, 1997.

Daudi, Abu, Kiprah Zuriat Muhammad Arsyad dalam Dakwah dan Pendidikan (Maulana Syekh Mubammad Arsyad), t.td.

Munadi, Fathullah, Syekh Muhammad Arsyad Al-Banjari: Dalam Konteks Kajian AlQuran di Nusantara, Banjarmasin, Antasari Press, 2010. 